\title{
The use of instructional design guidelines to increase effectiveness of postpartum hemorrhage simulation training
}

Citation for published version (APA):

de Melo, B. C. P., Falbo, A. R., Muijtjens, A. M. M., van der Vleuten, C. P. M., \& van Merrienboer, J. J. G. (2017). The use of instructional design guidelines to increase effectiveness of postpartum hemorrhage simulation training. International Journal of Gynecology \& Obstetrics, 137(1), 99-105. https://doi.org/10.1002/ijgo.12084

Document status and date:

Published: 01/04/2017

DOI:

10.1002/ijgo.12084

Document Version:

Publisher's PDF, also known as Version of record

Document license:

Taverne

Please check the document version of this publication:

- A submitted manuscript is the version of the article upon submission and before peer-review. There can be important differences between the submitted version and the official published version of record.

People interested in the research are advised to contact the author for the final version of the publication, or visit the DOI to the publisher's website.

- The final author version and the galley proof are versions of the publication after peer review.

- The final published version features the final layout of the paper including the volume, issue and page numbers.

Link to publication

\footnotetext{
General rights rights.

- You may freely distribute the URL identifying the publication in the public portal. please follow below link for the End User Agreement:

www.umlib.nl/taverne-license

Take down policy

If you believe that this document breaches copyright please contact us at:

repository@maastrichtuniversity.nl

providing details and we will investigate your claim.
}

Copyright and moral rights for the publications made accessible in the public portal are retained by the authors and/or other copyright owners and it is a condition of accessing publications that users recognise and abide by the legal requirements associated with these

- Users may download and print one copy of any publication from the public portal for the purpose of private study or research.

- You may not further distribute the material or use it for any profit-making activity or commercial gain

If the publication is distributed under the terms of Article $25 \mathrm{fa}$ of the Dutch Copyright Act, indicated by the "Taverne" license above, 
Obstetrics

\title{
The use of instructional design guidelines to increase effectiveness of postpartum hemorrhage simulation training
}

\author{
Brena C.P. de Melo ${ }^{1,2 *}$ | Ana R. Falbo ${ }^{1}$ | Arno M.M. Muijtjens ${ }^{2}$ | \\ Cees P.M. van der Vleuten ${ }^{2}$ | Jeroen J.G. van Merriënboer ${ }^{2}$
}

${ }^{1}$ Faculdade Pernambucana de Saúde and Centro de Atenção à Mulher, Instituto de Medicina Integral Prof. Fernando

Figueira, Centro de Atenção à Mulher, Recife, Brazil

${ }^{2}$ School of Health Professions

Education, Faculty of Health, Medicine and Life Sciences, Maastricht University, Maastricht, Netherlands

\section{${ }^{*}$ Correspondence}

Brena C.P. de Melo, Faculdade Pernambucana de Saúde and Centro de Atenção à Mulher at Instituto de Medicina Integral Prof. Fernando

Figueira, Recife, Brazil.

Email: bcpmelo@gmail.com

(-) This article includes a video abstract, available at https://www.youtube.com/ watch?v=4Q5kUFnsJ1Q.

\begin{abstract}
Objective: To compare learning outcomes of postpartum hemorrhage simulation training based on either instructional design guidelines or best practice.

Methods: A pretest-post-test non-equivalent groups study was conducted among obstetrics and gynecology residents in Recife, Brazil, from June 8 to August 30, 2013. The instructional design group included 13 teams, whereas the best practice group included seven teams. A standardized task checklist was used for scenario analysis and the proportion of correctly executed tasks compared (post-test minus pretest).

Results: The instructional design group scored higher than the best practice group for total number of tasks completed (median difference 0.46 vs $0.17 ; P<0.001$; effect size $[r]=0.72$ ). Similar results were observed for communication (median difference 0.56 vs $0.22 ; P=0.004 ; r=0.58$ ), laboratory evaluation (median difference 0.83 vs 0.00 ; $P<0.001 ; r=0.76$ ), and mechanical management (median difference 0.25 vs -0.15 ; $P=0.048 ; r=0.39)$. Speed of learning was also increased. The median differences were 0.20 for the instructional design group compared with 0.05 for the best practice group at 60 seconds $(P=0.015 ; r=0.49)$, and 0.49 versus $0.26 \quad(P=0.001 ; r=0.65)$ at 360 seconds.

Conclusion: The use of simulation training for postpartum hemorrhage that was based on instructional design guidelines yielded better learning outcomes than did training based on best practice.

\section{KEYWORDS}

Education; Instructional design; Postpartum hemorrhage; Simulation training; Situational awareness; Training
\end{abstract}

\section{1 | INTRODUCTION}

Postpartum hemorrhage (PPH) is the leading cause of maternal mortality worldwide, particularly among deaths that are considered avoidable. ${ }^{1}$ Frequently reported assistance failures associated with preventable PPH include delay in diagnosis, poor communication, insufficient teamwork, and lack of adequate education and training. ${ }^{2,3}$ Simulation training has emerged as a widespread strategy to overcome such failures. Systematic reviews of simulation-based healthcare education debate the best way to deliver instructional features to ensure optimal effectiveness of training. ${ }^{4,5}$ Nonetheless, a growing body of evidence recommends that training formats should be based on reliable educational principles, particularly instructional design guidelines. $^{6}$

The Four-Component Instructional Design model $^{7}$ and Merrill's First Principles of Instruction ${ }^{8}$ summarize the main guidelines. According to the guidelines, effective instruction should contain authentic, relevant, and daily real-world problems, emphasize practice at 
different levels of complexity, and provide feedback and diminishing instructional support through training. ${ }^{7}$

When devising a PPH simulation training format based on instructional design guidelines, the learning objectives should be clearly identified and summarized in strategies that aim to overcome recurrent assistance failures. Such learning objectives include situational awareness enhancement, ${ }^{9}$ improvement of both communication and teamwork skills and attitudes, ${ }^{10}$ and reinforcement of specific knowledge and skills regarding the correct management of patients with $\mathrm{PPH} .{ }^{1-3}$

The aim of the present study was to test the hypothesis that a PPH simulation training program based on instructional design guidelines would lead to better learning outcomes than the use of a simulation training program based on best practice.

\section{2 | MATERIALS AND METHODS}

A pretest-post-test non-equivalent groups study was conducted at two of the local teaching hospitals in Recife, Brazil-Instituto de Medicina Integral Prof. Fernando Figueira and Hospital das Clínicas, Universidade Federal de Pernambuco-from June 8 to August 30, 2013. Obstetrics and gynecology residents working at any of the five local teaching hospitals in Recife were considered eligible and invited to participate. These hospitals provide high-risk maternity services and report an equivalent number of deliveries per resident. The present study was approved by the Ethics Committee of the Instituto de Medicina Integral Prof. Fernando Figueira. All participants provided signed informed consent at the training session.

Of all eligible residents, half worked at the Instituto de Medicina Integral Prof. Fernando Figueira. Therefore, residents from this center formed the entire instructional design group $(n=36)$. They were divided into 13 teams: four teams of two individuals and nine teams of three individuals. One participant had to leave the instructional design group for personal reasons before undergoing the post-test. Participants assigned to the best practice group ( $n=18$ ) came from the other four maternity hospitals and underwent training at Hospital das Clínicas, Universidade Federal de Pernambuco. These participants were divided into seven teams: three teams of two individuals and four teams of three individuals. A similar distribution among teams by age, sex, and year of residency was noted for both training formats. Training occurred in half-day sessions, with one or two teams at each.

According to Merrill, ${ }^{8}$ efficient instruction should engage learners in solving real-world problems, activate existing knowledge as a foundation for new knowledge, demonstrate the new knowledge to the learner, provide opportunities for applying the new knowledge, and integrate the new knowledge into the trainee's world. Additionally, the Four-Component Instructional Design model $^{7}$ claims that four interrelated components are essential for a training program: learning tasks, supportive information, just-in-time information (i.e. information provided to the learner at the moment that it is needed), and part-task practice. To clearly establish the learning objectives of the present study, a PPH guideline was created through discussion with a focus group (formed of invited obstetricians and anesthesiologists who were
TABLE 1 Examples of the expected tasks.

\begin{tabular}{|l|l|}
\hline Subscale & Expected task \\
\hline Communication & $\begin{array}{c}\text { The participant introduced himself or } \\
\text { herself to the patient, explained the } \\
\text { actions to the patient, and asked the } \\
\text { patient about comorbidities, medica- } \\
\text { tions, and allergies }\end{array}$ \\
\hline Teamwork & $\begin{array}{c}\text { Team-support behavior and adequate } \\
\text { sharing of information }\end{array}$ \\
\hline Vital signs & $\begin{array}{c}\text { Checked heart rate, blood pressure, and } \\
\text { rechecked vital signs }\end{array}$ \\
\hline Venous access & $\begin{array}{l}\text { Large caliber intravenous line, order blood } \\
\text { samples }\end{array}$ \\
\hline Laboratory evaluation & $\begin{array}{c}\text { Complete blood count; renal and liver } \\
\text { function tests; blood type and }\end{array}$ \\
\hline cross-match
\end{tabular}

supervisors of residents) and was based on the most up-to-date clinical evidence. ${ }^{1-3}$ Table 1 provides examples of the expected tasks by subscale.

Figure 1 outlines the two training formats and the clinical case scenarios. The instructional design group format comprised eight steps, including three training scenarios with increasing levels of complexity. An obstetrician was present in the delivery room to provide "over the shoulder" just-in-time guidance and corrective feedback to participants, whenever necessary. The best practice group received the PPH guideline before undergoing a three-step training format, one of which was a training scenario. This format replicated the best PPH simulation training ${ }^{11}$ and was creating using articles identified in the literature. Seven experts (five from an educational background and two who had healthcare training) used a rating scale based on Merrill's First Principles of Instruction ${ }^{8}$ to analyze the articles from an instructional design perspective.

The pretest and post-test scenarios were the same for both groups. They were offered immediately before and after the training scenarios, and presented an intermediate level of complexity. The third instructional design format training scenario (most complex scenario) was identical to the sole training scenario used in the best practice format and corresponded with a previous description. ${ }^{11}$

All scenarios were scripted as PPH after vaginal delivery and included a standardized patient, a standardized nurse, and a part-task pelvis simulator (EVA Simulador Pós-Parto; ProDelphus, Olinda, Brazil). Consequently, the nature of potentially expected tasks comprised communication, teamwork, and clinical management. The low-cost part-task simulator allowed variation in the site (vaginal laceration, uterus, or both) and intensity of the bleed, and was managed by the standardized patient. The standardized nurses provided the 
Instructional design format

Best practice format

Received PPH guideline before training

Pretest scenario - intermediate complexity PPH case

First-degree laceration and a mildly hypotonic responsive uterus + initial stages of hypovolemic shock

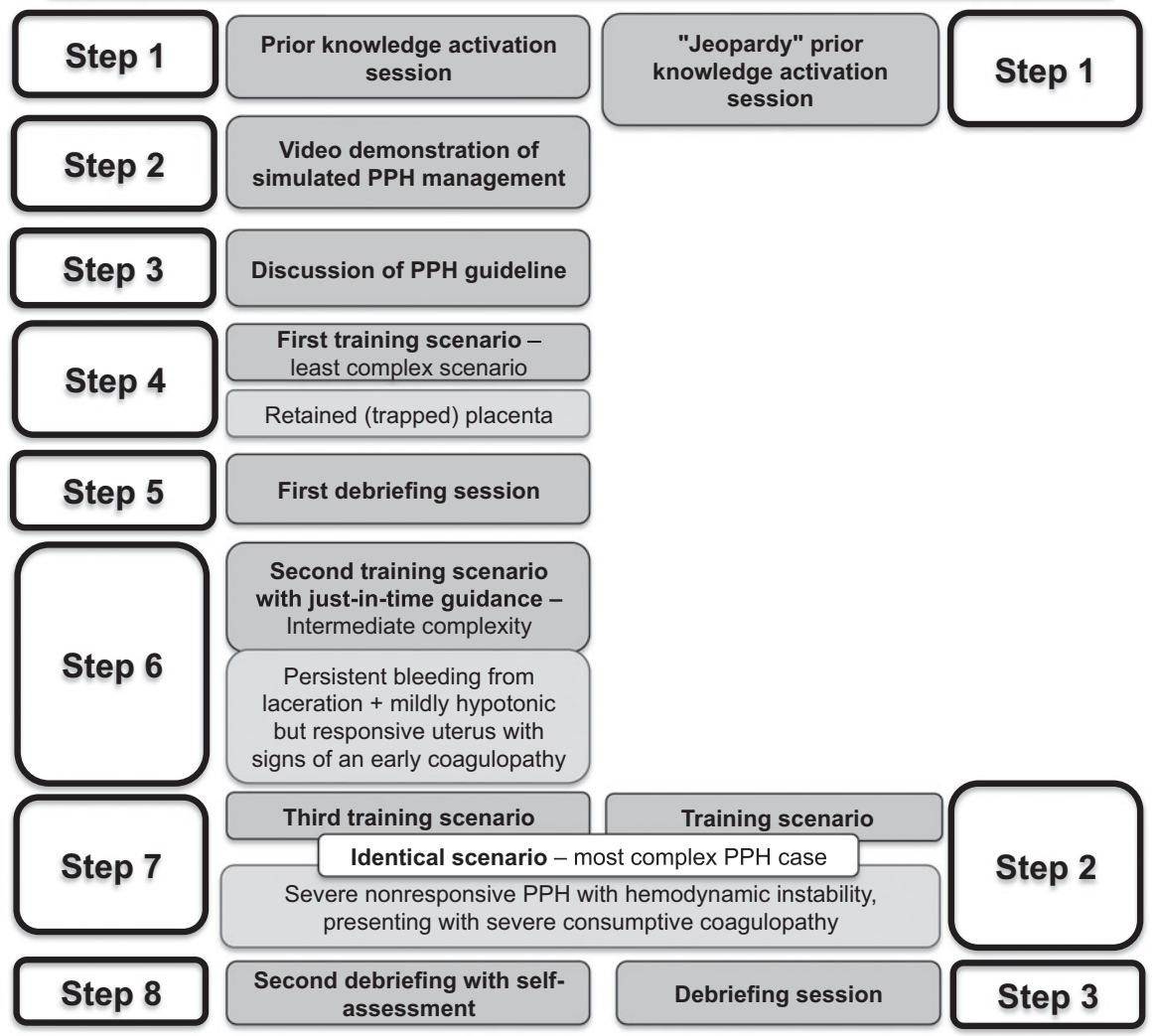

Post-test scenario - intermediate complexity PPH case

Retained products of conception with a mildly hypotonic responsive uterus + initial stages of hypovolemic shock

FIGURE 1 The steps used in the instructional design and best practice formats for PPH simulation training. The pretest and post-test PPH scenarios were identical for both training groups. Abbreviation: PPH, postpartum hemorrhage.

participants with clinical data (vital signs, results of laboratory evaluation, and uterine responses). Both the standardized patients and nurses (who were all volunteer healthcare personnel) received the script for each scenario in advance of training to allow for rehearsal.

At each training session, participants were welcomed, introduced to the training equipment, and asked to suspend their disbelief (i.e. act as though the simulation was a real-life clinical case) and not to share any information about the program until the end of all training sessions. Participants were then asked to form the teams outlined above and provided with the pretest scenario. All scenarios were either run for a maximum of 900 seconds or else interrupted at the point that the team diagnosed and corrected the main cause of the bleeding.

All scenarios were video recorded for either debriefing purposes (the training scenarios) or to enable future analysis for scoring and comparisons (the pretest and post-test scenarios). Two obstetricians were present at each session: BdM attended all the training sessions and 10 additional obstetricians alternated as the second content expert. Each pair of obstetricians was responsible for rating the pretest and post-test scenarios video recordings for each of the teams that they supervised. The experts received the checklists of expected tasks at the beginning of each scenario, whereas the participants received them immediately after attending the first and third training scenario for debriefing purposes.

A standardized checklist of expected tasks (derived from the PPH guideline outlined previously) for each scripted scenario was used in the analysis. A task was considered to be executed if it had been performed by at least one participant (e.g. ordering laboratory evaluation) or, depending on the nature of the task, by all members of the team (i.e. teamwork tasks). Consequently, the unit of analysis was the team rather than individual participants.

At pretest, 38 tasks were expected to be executed; at post-test, 39 were expected. These tasks were distributed among eight learning 
subscales: communication ( 9 pretest/9 post-test), teamwork (6/6), vital signs (3/3), venous access (3/3), laboratory evaluation $(6 / 6)$, mechanical management (4/5), drug management (6/6), and surgical management (1/1). Most pretest and post-test tasks were coincident, particularly for the first five subscales. The expected tasks varied according to the scripted case for the remaining three subscales. The number of tasks correctly executed by each team was registered in total, per subscale, and per time elapsed (in seconds). The entrance of the first team member into the delivery room defined the start of the process ( 0 seconds). The proportion of correct tasks was calculated for each of these landmarks. The medians of these proportions were used for comparison (instructional design group vs best practice group).

A generalizability analysis was used to estimate inter-rater reliability; a value of 0.93 for one rater (BdM) was considered to represent sufficiently high reliability. ${ }^{12}$

The timepoints used to compare groups of teams were 60,360 , and 900 seconds. The 60 -second checkpoint reflected the "golden minute" concept in neonatal resuscitation guidelines; early initiation of basic resuscitation interventions are thought to be essential to prevent progression to circulatory colapse. ${ }^{13}$ The 360 -second landmark corresponded to an additional 300 seconds, during which correct identification of the cause of bleeding and corresponding preliminary actions were expected. ${ }^{14,15}$ The 900 -second checkpoint was the cutoff for the amount of time required to assess how the team managed the PPH case.

The data were analyzed using SPSS version 22 (IBM, Armonk, NY, USA). The post-test minus pretest difference in the median of the proportions of executed tasks was compared between the two groups for the various landmarks. The Mann-Whitney $U$ test was used for comparison, with a $P$ value of less than 0.05 considered statistically significant. The effect size $(r)$ was also calculated, ${ }^{16}$ and its magnitude was classified as small (0.10), medium (0.30), and large $(\geq 0.50) .{ }^{17}$

\section{3 | RESULTS}

Overall, 54 (55.1\%) of the 98 eligible residents attended training during their off-duty hours. Data regarding the proportion of all tasks correctly executed by the two groups is presented in Table 2. Both groups presented similar median proportions at pretest. However, when comparing the proportion of all tasks executed from pretest to post-test, a greater increase was found for the instructional design group (median difference 0.46 , interquartile range [IQR] 0.147) than for the best practice group (median difference 0.17, IQR 0.262). The $U$ value for the comparison was $5.0(P<0.001)$ and the effect size was 0.72 .

The instructional design group exhibited a statistically significant greater increase from pretest to post-test than did the best practice group for three of the eight subscales: communication, laboratory evaluation, and mechanical management (Table 2). No comparison was made for the surgical management subscale because it comprised only one task, both at pretest and post-test. Additionally, at post-test, the expected task involved manual removal of the retained placental tissue from the part-task simulator. Some of the teams-five from the instructional design group and three from the best practice group-did not complete this task because they did not want to damage the simulated pelvis. Owing to the heterogeneity of the supervisors' approach to overcoming this problem during training, it was decided to exclude the surgical management subscale from the analysis.

Figure 2 presents the post-test minus pretest difference in the proportion of tasks completed by both the instructional design and best practice groups of teams after 60 and 360 seconds. A greater increase from pretest to post-test was observed for the instructional design group versus the best practice group at both time points. As shown in Table 2, the instructional design group showed a greater increase of correctly performed tasks after 60 seconds (median difference 0.20, IQR 0.131) than did the best practice group (median difference 0.05, IQR 0.092). The $U$ value for the comparison was $18.0(P=0.015)$ and the effect size was 0.49 , indicating that the instructional design group was not only performing more tasks correctly but also earlier in the process than the best practice group. A similar result was observed after 360 seconds. The median differences for the instructional design and best practice groups were 0.49 (IQR 0.135) and 0.26 (IQR 0.237). The $U$ value for the comparison was $9.0(P=0.001)$ and the effect size was 0.65 .

\section{4 | DISCUSSION}

The present study demonstrated the effectiveness of the instructional design format for PPH simulation training. Participants who received such training exhibited a substantially greater increase in the number of executed tasks, and within a shorter time frame, than did participants assigned to the best practice training format. Thus, the findings of the present study confirmed the stated hypothesis.

The instructional design format offered several features not included in the best practice format. These features included broad content discussion at the prior knowledge step, multiple learning strategies, video demonstration of the expected tasks; clinical variation, increasing level of complexity, just-in-time information, corrective feedback, decreasing support, and two debriefings, with self-assessment in the second debriefing session. All these aspects are regarded to be effective for learning through simulation ${ }^{7,18,19}$ with particular recommendation by the Four-Component Instructional Design model. ${ }^{20}$ Furthermore, potential confounding variables were controlled by delivering both training formats in an equivalent hospital environment. $^{21}$

Although the ideal design for the present study would have been to randomly allocate participants to the two training formats, the locally elevated rates of PPH-related maternal morbidity and mortality required prioritization of a large number of participants through flexibility of the training schedule. Of note, however, both groups displayed similar median proportions at pretest.

The present findings could contribute to minimizing the recognized gap in comparative effectiveness research on simulation training formats. As previously noted, ${ }^{22,23}$ an extensive body of evidence provides plain description of training outcomes, ${ }^{24}$ or comparison of 


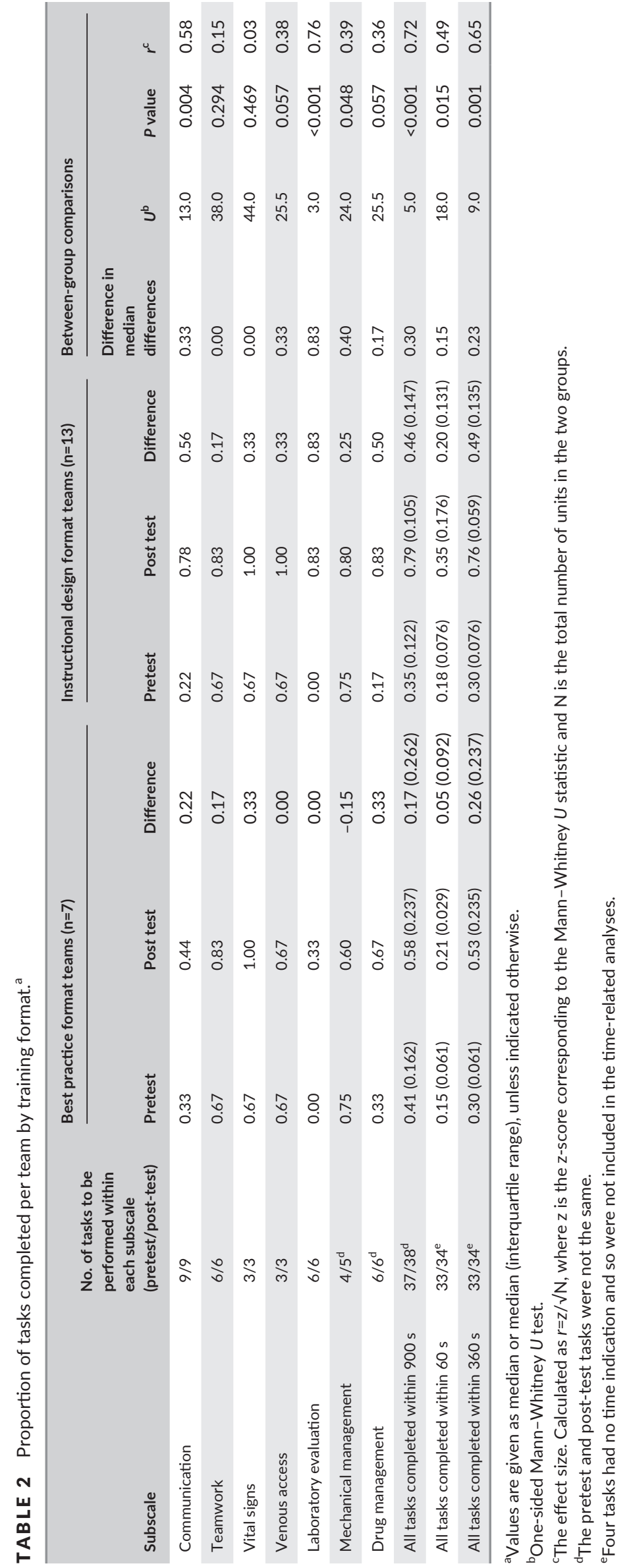



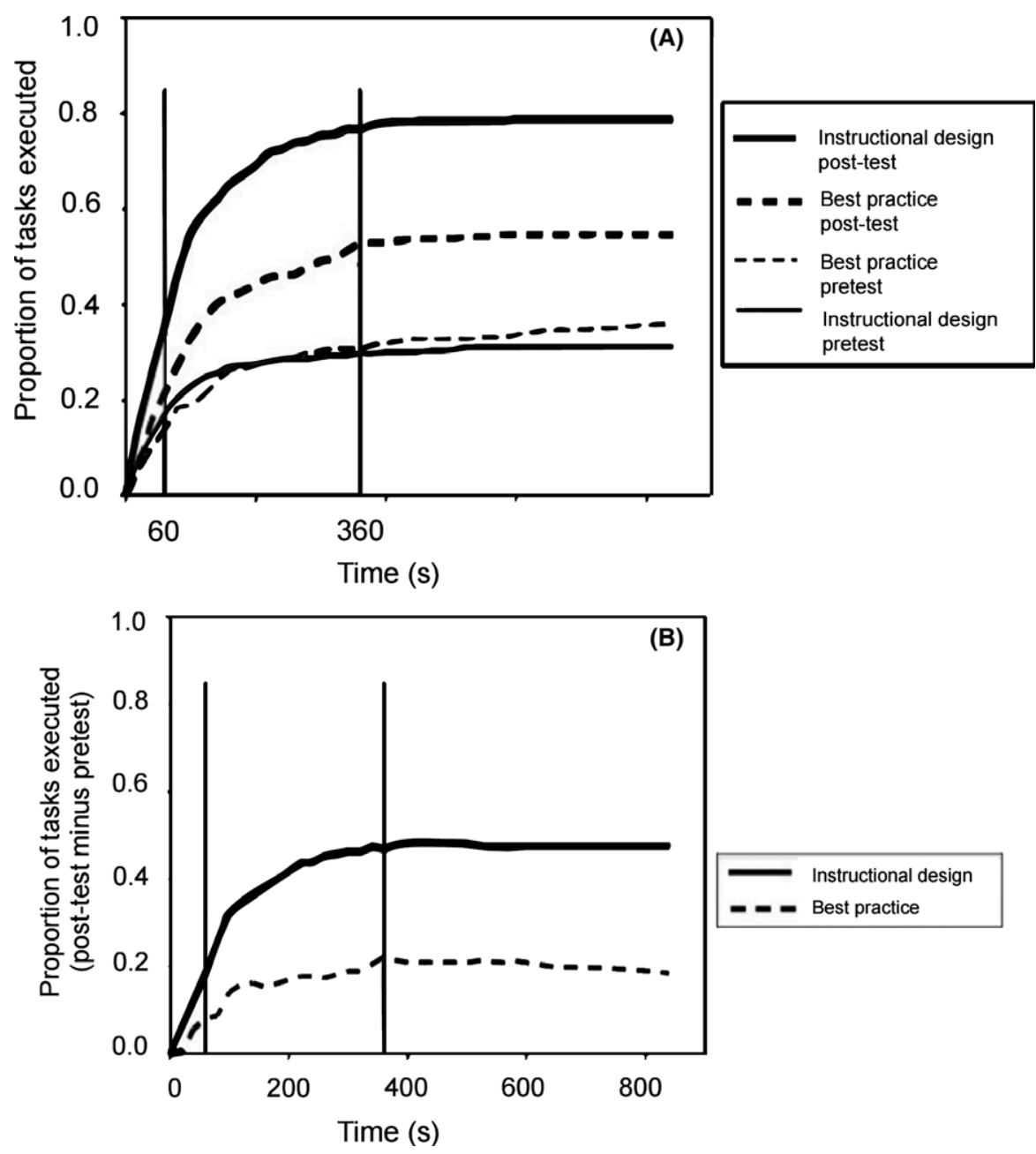

FIGURE 2 The proportion of tasks completed by teams enrolled in the best practice $(n=7)$ and instructional design ( $n=13)$ groups. (A) The pretest and post-test proportions over time. (B) The between-group differences (post-test minus pretest).

different instructional sequences, ${ }^{25}$ but not of different instructional design features.

The level of detail in the present findings allowed some interpretation. For example, the marked increase for the laboratory evaluation subscale could be extrapolated as ability acquired by the trainees to anticipate, recognize, and intercept ongoing management flaws and potential patient compromise. This acquired ability might lead to increased situational awareness, ${ }^{9}$ a factor that is frequently jeopardized in the substandard care of patients with $\mathrm{PPH}^{2,3}$

The use of a portable part-task simulator, ordinary labor assistance material, portable filming, and a video exhibition device (electronic notebook) are all elements that favor future training replication and portability. With regard to $\mathrm{PPH}$, these things could be of particular relevance, given that the most challenging aspects of this condition are its unpredictability and omnipresence. ${ }^{1}$ Therefore, an effective portable PPH training package might increase the proportion of trained personnel in an undemanding manner. Moreover, the essential structure to the instructional design training format could be easily adapted to other obstetric emergencies, clinical content, and types of trainees.
Despite the nonsignificant differences observed for some of the subscales assessed in the present study, there was an increase in the overall proportion of tasks executed from pretest to post-test. For the teamwork subscale, measurement difficulty is a well-recognized issue owing to its multiple dimensions. ${ }^{5,26}$ The low number of expected tasks for the both the vital signs and venous access subscales could have limited the comparison; however, all the expected tasks were correctly executed in the instructional design group. The unanticipated finding of a negative value for the mechanical management subscale among the best practice group might be attributed to the unfamiliarity of these trainees with the simulator, given that they had attended fewer scenarios then the instructional design group. The time-on-task difference between training formats could be highlighted as a potential limitation because it reflects a core difference between current best practice and instructional design training formats.

In conclusion, the findings of the present study indicated the importance of applying established learning principles, such as instructional design guidelines, when designing simulation training formats. Optimum training time and the impact of particular features on knowledge transfer and clinical outcomes remain to be explored. 


\section{AUTHOR CONTRIBUTIONS}

BdM was involved in study conception, execution, and organization; training; data collection, analysis, and interpretation; and writing and reviewing of the manuscript. AF was involved in data analysis and interpretation, as well as writing and reviewing of the manuscript. AM was involved in the execution and interpretation of the statistical analyses, as well as reviewing the manuscript. CvdV and JvM were involved in study conception and organization; data analysis and interpretation; and reviewing the manuscript.

\section{ACKNOWLEDGMENTS}

The present study was financially supported by Faculdade Pernambucana de Saúde and Instituto de Medicina Integral Prof. Fernando Figueira, Recife, Brazil.

\section{CONFLICT OF INTEREST}

The authors have no conflicts of interest.

\section{REFERENCES}

1. World Health Organization. WHO recommendations for the prevention and treatment of postpartum haemorrhage. 2012.

2. Knight $M$, Kenyon S, Brocklehurst $P$, Neilson J, Shakespeare J, Kurinczuk JJ, eds; on behalf of MBRRACE-UK. Saving lives, improving mothers' care - lessons learned to inform future maternity care from the UK and Ireland confidential enquiries into maternal deaths and morbidity 2009-12. Oxford, UK. 2014.

3. Bohlmann MK, Rath W. Medical prevention and treatment of postpartum hemorrhage: A comparison of different guidelines. Arch Gynecol Obstet. 2014;289:555-567.

4. Cook DA, Hamstra SJ, Brydges R, et al. Comparative effectiveness of instructional design features in simulation-based education: Systematic review and meta-analysis. Med Teach. 2013;35:e867-e898.

5. Mérien A, van de Ven J, Mol BW, Houterman S, Oei SG. Multidisciplinary team training in simulation setting for acute obstetric emergencies: A systematic review. Obstet Gynecol. 2010;115:1021-1031.

6. Ameh CA, van den Broek N. Making it happen: Training health-care providers in emergency obstetric and newborn care. Best Pract Res Clin Obstet Gynaecol. 2015;29:1077-1091.

7. Van Merriënboer JJG, Kirschner PA. Ten steps to complex learning: A systematic approach to four-component instructional design. New York: Routledge; 2012:xii, 332.

8. Merrill MD. First Principles of Instruction: Identifying and designing effective, efficient and engaging instruction San Francisco, CA. USA: Pfeiffer; 2013.
9. Edozien LC. Situational awareness and its application in the delivery suite. Obstet Gynecol. 2015;125:65-69.

10. Cornthwaite K, Edwards S, Siassakos D. Reducing risk in maternity by optimising teamwork and leadership: An evidence-based approach to save mothers and babies. Best Pract Res Clin Obstet Gynaecol. 2013;27:571-581.

11. Clark EA, Fisher J, Arafeh J, Druzin M. Team training/simulation. Clin Obstet Gynecol. 2010;53:265-277.

12. Streiner DL, Norman GR. Health measurement scales: A practical guide to their development and use. Oxford, New York: Oxford University Press; 2008:xvii, 431p.

13. Ersdal HL, Mduma E, Svensen E, Perlman JM. Early initiation of basic resuscitation interventions including face mask ventilation may reduce birth asphyxia related mortality in low-income countries: A prospective descriptive observational study. Resuscitation. 2012;83:869-873.

14. Crowe SD, Faulkner B. Lean management system application in creation of a postpartum hemorrhage prevention bundle on postpartum units. Obstet Gynecol. 2014;123:45S-45S.

15. Deering SH, Chinn M, Hodor J, Benedetti T, Mandel LS, Goff B. Use of a postpartum hemorrhage simulator for instruction and evaluation of residents. J Grad Med Educ. 2009;1:260-263.

16. Field A. Discovering Statistics Using SPSS. London: Sage; 2013.

17. Cohen J. Statistical power analysis for the behavioral sciences. Hillsdale, NJ: L. Erlbaum Associates; 1988:xxi, 567p.

18. Issenberg SB, McGaghie WC, Petrusa ER, Lee GD, Scalese RJ. Features and uses of high-fidelity medical simulations that lead to effective learning: A BEME systematic review. Med Teach. 2005;27:10-28.

19. McGaghie WC, Issenberg SB, Petrusa ER, Scalese RJ. Effect of practice on standardised learning outcomes in simulation-based medical education. Med Educ. 2006;40:792-797.

20. Maggio LA, Cate OT, Irby DM, O'Brien BC. Designing evidence-based medicine training to optimize the transfer of skills from the classroom to clinical practice: Applying the four component instructional design model. Acad Med. 2015;90:1457-1461.

21. Cook DA. Avoiding confounded comparisons in education research. Med Educ. 2009;43:102-104.

22. McGaghie WC, Issenberg SB, Cohen ER, Barsuk JH, Wayne DB. Does simulation-based medical education with deliberate practice yield better results than traditional clinical education? A meta-analytic comparative review of the evidence. Acad Med. 2011;86:706-711.

23. Cook DA, Hatala R, Brydges R, et al. Technology-enhanced simulation for health professions education a systematic review and metaanalysis. JAMA J Am Med Assoc. 2011;306:978-988.

24. Fialkow MF, Adams CR, Carranza L, Golden SJ, Benedetti TJ, Fernandez R. An in situ standardized patient-based simulation to train postpartum hemorrhage and team skills on a labor and delivery unit. Simul Healthc. 2014;9:65-71.

25. Stefaniak JE, Turkelson CL. Does the sequence of instruction matter during simulation? Simul Healthc. 2014;9:15-20.

26. Salas E, Grossman R, Hughes AM, Coultas CW. Measuring team cohesion: Observations from the science. Hum Factors. 2015;57: 365-374 